\title{
Prediction of Sound Insulation of Sandwich Partition Panels by Means of Artificial Neural Networks
}

\author{
Naveen GARG ${ }^{(1)}$, Siddharth DHRUW ${ }^{(2)}$, Laghu GANDHI ${ }^{(3)}$ \\ (1) CSIR-National Physical Laboratory \\ New Delhi - 110012, India; e-mail: ngarg@nplindia.org \\ (2) National Institute of Technology, Hamirpur \\ 1601 Hamirpur - 177 005, India \\ (3) National Institute of Technology, Kurukshetra \\ Kurukshetra - 136 119, India \\ (received July 21, 2016; accepted May 11, 2017)
}

\begin{abstract}
The paper presents the application of Artificial Neural Networks (ANN) in predicting sound insulation through multi-layered sandwich gypsum partition panels. The objective of the work is to develop an Artificial Neural Network (ANN) model to estimate the $R_{w}$ and STC value of sandwich gypsum constructions. The experimental results reported by National Research Council, Canada for Gypsum board walls (HAlliwell et al., 1998) were utilized to develop the model. A multilayer feed-forward approach comprising of 13 input parameters was developed for predicting the $R_{w}$ and STC value of sandwich gypsum constructions. The Levenberg-Marquardt optimization technique has been used to update the weights in back-propagation algorithm. The presented approach could be very useful for design and optimization of acoustic performance of new sandwich partition panels providing higher sound insulation. The developed ANN model shows a prediction error of $\pm 3 \mathrm{~dB}$ or points with a confidence level higher than $95 \%$.
\end{abstract}

Keywords: weighted sound reduction index, $R_{w}$; Sound Transmission Class, STC.

\section{Introduction}

The sound transmission through sandwich gypsum constructions has always been a grey area of research for its interior applications for noise abatement and control. There have been many studies (WARNOCK, 1985; 1990; 1993; 1998; WARNOCK, QUIRT, 1995; 1997; Bradley, Birta, 2001; Bradley, Gover, 2011; GUILLEn et al.., 2008; Uris et al., 1998; HALLIWELL et al., 1998; QUiRT et al., 1995; Roozen et al., 2015) reported so far, especially those reported by National Research Council (NRC), Canada, that focus on the enhancement of sound transmission loss of sandwich gypsum constructions and the use of masonry walls in conjunction with the dry wall technology. Thus, the parametric sensitivity of various factors controlling the sound insulation is instrumental in designing sandwich constructions for optimizing the sound insulation characteristics (GARG et al., 2013a; 2013b; 2013c; 2014a). The method of attachment of gypsum boards via steel studs (staggered, with resilient channels or via double studs), stud spacing, thickness and density of absorptive material used etc. are the pivotal factors affect- ing the sound insulation. The sound insulation characteristics are shown in terms of single-number rating: Sound Transmission Class (STC) and weighted sound reduction index, $R_{w}$. Also, there have been various analytical models reported so far for prediction of sound insulation properties of sandwich multilayered constructions (Sharp, 1978; Bradley, Birta, 2001; António et al., 2003; WAng et al., 2005; PeLLicier, Trompette, 2007; GARG et al., 2013a; 2013b; ZHOU et al., 2013; GARG et al., 2014a; 2015a). BALLAGH (2004) studies evidently revealed a mean difference in $\mathrm{STC} / R_{w}$ between measurement and theory less than $0.5 \mathrm{~dB}$ and $90 \%$ of results were found to lie within $\pm 2.5 \mathrm{~dB}$. Kurra (2012) discussed the suitability of three models: Insul $S W$ based on Sharp model with some modifications, Acousys $S W$ using the transfer matrix and windowing technique and $F M u$ lay $S W$ based on improved impedance model. Comparison of the calculated data with the experimental data shows that Insul model yields in slightly better compatibility with experimental results, however the correlation coefficients are rather high for all the models. The Acousys and FMulay are capable of calcula- 
tions for more complex lagging structures, whereas Insul is limited to the applications of common building elements (KURRA, 2001; 2012; Insul (2017); AcouSYS (2017)). Statistical Energy analysis (SEA) has been also employed by some researchers to predict the sound transmission loss through sandwich panels (LYON, DEJong, 1995; Crocker et al., 1999; Craik, SMith, 2000; WANG et al., 2010). Thus, it is evident from previous studies that analytical models to a larger extent have filled the gap between the experimentation and theoretical predictions and have thus minimized the necessity of cumbersome and expensive experimentations required in reverberation chambers. However, inspite of all these facts, alternative strategies such as soft computing skills play a very significant role in predictions as it has been proven in some previous studies reported in acoustic field (LIN et al., 2009; NANNARIELlO, FRICKE, 1999; 2001; NANNARIELlO et al., 2001; Mungiole et al., 2006; Buratti et al., 2013). BurATti et al. (2013) developed an Artificial Neural Network (ANN) model to estimate the $R_{w}$ value of wooden windows based on a limited number of window parameters. A 5-10-10-1 neuron configuration was determined as optimal one with a test RMS error of $2.4 \%$. The dynamic behaviour of neural networks (NUCARA et al., 2002; GIVARGiS KARIMI, 2010), capability to model non linear relationships and flexibility to use any number of input and output parameters make them useful for prediction of sound insulation characteristics of multi-layered partition panel constructions. Besides that the analytical models do have certain limitations in prediction accuracy especially in case of multilayered constructions.

The present work describes the application of Artificial Neural Networks (ANN) in modelling sound transmission characteristics of sandwich gypsum panel constructions. The sound insulation characteristics of these constructions are analyzed in terms of widely used single-number ratings: Sound Transmission Class (STC) and weighted sound reduction index, $R_{w}$. Both quantities are based on shifting a prescribed rating contour to match the measured values of sound transmission loss versus frequency following rules that specify the maximum allowed sum of deficiencies below the contour. For the STC rating, a limit on the maximum allowed deficiency below the rating contour in a single frequency band is also specified (PARK, BRADLEY, 2009).

\section{Materials and methods}

The present work utilized the experimental results reported by National Research Council, Canada for Gypsum board walls (HALLIWELL et al., 1998; QUIRT et al., 1995). The measurements reported in NRC, Canada reports (HALLIWELl et al., 1998; QUIRT et al., $1995)$ were made in the suite of reverberation cham- bers in building of the Institute for Research in Construction of the National Research Council, Canada. The volume of the source room was $65 \mathrm{~m}^{3}$ and that of adjacent receiving room was $250 \mathrm{~m}^{3}$. The wall test opening measured $3.05 \times 2.44 \mathrm{~m}$. Tests were done in accordance with the requirements of ASTM E90-1990 and of ISO 140/III 1978 (E). The Sound Transmission Class was determined in accordance with ASTM standard classification E413-1987. The number of gypsum layers on either side was one or two, while the stud types were wood or steel studs. The distance between studs was varied at two levels: $406 \mathrm{~mm}$ and $610 \mathrm{~mm}$ on center. The number of resilient channels was one, two or none and the spacing between the resilient channels was varied as $406 \mathrm{~mm}$ or $610 \mathrm{~mm}$ on center. The surface density of partition panels tested varied from $15.6 \mathrm{~kg} / \mathrm{m}^{2}$ to $50.23 \mathrm{~kg} / \mathrm{m}^{2}$. The sound absorbing material used was cellulose blown, mineral fibre and glass fibre of varied thickness. $90 \mathrm{~mm}$ blown cellulose of density $49.3 \mathrm{~kg} / \mathrm{m}^{3}$ and airflow resistivity $33000 \mathrm{mks}$ rayls $/ \mathrm{m}$ was used. The mineral fibre batt used was $40 \mathrm{~mm}$ batt of density $51.9 \mathrm{~kg} / \mathrm{m}^{3}$ and airflow resistivity $15000 \mathrm{mks}$ rayls $/ \mathrm{m} ; 65 \mathrm{~mm}$ batt of density $36.7 \mathrm{~kg} / \mathrm{m}^{3}$ and airflow resistivity $11400 \mathrm{mks}$ rayls $/ \mathrm{m}$ and $90 \mathrm{~mm}$ batt of density $33.3 \mathrm{~kg} / \mathrm{m}^{3}$ and airflow resistivity $12700 \mathrm{mks}$ rayls $/ \mathrm{m}$. The glass fibre batt used were $65 \mathrm{~mm}$ batt of density $11.7 \mathrm{~kg} / \mathrm{m}^{3}$ and airflow resistivity $3600 \mathrm{mks}$ rayls $/ \mathrm{m} ; 96 \mathrm{~mm}$ batt of density $12.2 \mathrm{~kg} / \mathrm{m}^{3}$ and airflow resistivity $4800 \mathrm{mks}$ rayls $/ \mathrm{m} ; 150 \mathrm{~mm}$ batt of density $11.2 \mathrm{~kg} / \mathrm{m}^{3}$ and airflow resistivity $4300 \mathrm{mks}$ rayls/m (HALLIWELL et al., 1998).

Thirteen input parameters were chosen, i.e.: number of gypsum layer on one side, number of gypsum layers on another side, stud type, distance between studs [mm], sound absorbing material type; sound absorbing material $[\mathrm{SAB}]$ density $\left[\mathrm{kg} / \mathrm{m}^{3}\right]$, sound absorbing material resistivity [mks rayls $/ \mathrm{m}]$, sound absorbing material thickness [mm], thickness of gypsum board [mm], surface density $\left[\mathrm{kg} / \mathrm{m}^{2}\right]$, number of resilient channels, air gap and spacing between the resilient channels; while the output parameters considered were STC and $R_{w}$ exclusively. It may be noted that although the report shows the sound insulation results for 350 sandwich partition panel constructions, yet the present study utilized the data of 283 partition panel constructions only. This was due to the fact that some sandwich constructions don't fit exactly with the input parameters as required for developing the ANN model. For instance, some partition constructions had cross brace between two studs, some had different thickness of sound absorbing material whereby the properties like density, air flow resistivity are not clearly mentioned in the NRC, Canada reports (HALLIWELl et al., 1998; QUIRT et al., 1995) and as such a uniform database of 283 tested materials only was utilized for developing an ANN model. 


\section{Development of ANN model}

A neural network consists of interconnected group artificial neurons organized into multiple layers: one input, one or more hidden layers and one output layer. The basic processing elements of neural networks are the artificial neurons. The inputs multiplied by the connection weights (adjusted) are combined and passed through a transfer function to produce the output for that neuron (GHAFFARI et al., 2006). The activation function acts on the weighted sum of the neurons inputs. Thus, a neural network is trained to map a set of input data and output data by iterative adjustments of the weights. The most commonly used transfer function is the sigmoid (logistic) function, wherein the activation signal is passed through transfer function to produce a single output of the neuron. The back propagation algorithm used widely trains a given feed-forward multilayer neural network for a given set of input patterns. When each entry of the sample set is presented to the network, the network examines its output response to the sample input pattern. The output response is then compared to the known and desired output and the error value is calculated, based on which the connection weights are adjusted until error reaches a specified level of accuracy. Once the network is trained, tested and validated, it is ready for predictions. The details of the ANN modelling can be found in (GARG et al., 2015b; ZhANG et al., 1998; CAI et al., 2009 and GARG et al., 2016). In present study, the data set of sound insulation of sandwich gypsum board partition panel measurements (283 observations) is divided into training data (70\%), testing data (15\%) and validation data (15\%). The multilayer feed forward back propagation (BP) neural network has been trained by LevenbergMarquardt (L-M) algorithm to develop an Artificial Neural Network (ANN) model for predicting STC and $R_{w}$ of sandwich multi-layered constructions. A complete representation of all the training data (input and target data) is known as epoch which is repeated until the network reaches a predefined goal of least mean squared error.Trainlm is the network training function that updates weights and bias values according to Levenberg-Marquardt (L-M) optimization. It is often the fastest back propagation algorithm and is highly recommended as a first choice supervised algorithm, although it does require more memory than other algorithms (https://in.mathworks.com). The activation functions used in the learning algorithms for feed forward ANN training play an important role in determining the speed of training (LECUN et al., 1998; Duch, JANKOWsKI, 1999). The logsig activation function used in the present case to introduce non linearity in the model was observed to provide the lowest mean squared error. The training set consists of examples used for learning i.e. fitting the weights for desired output, validation data is used to tune the network parameters and the test dataset is used to assess the performance after leaning (CAI et al., 2009). The number of hidden layers is difficult to decide, but typically no more than one hidden layers is used in a network (Hush, Horne, 1993). The network is run with various trials using different number of neurons in hidden layer. The optimum number of neurons in hidden layer for which the performance criteria, i.e. Mean Squared Error (MSE) and correlation coefficient $(R)$ between the measured and predicted data is chosen. The Mean Squared Error is expressed by following equation:

$$
\operatorname{MSE}=\frac{1}{k} \sum_{p=1}^{k} \delta_{o p}^{2},
$$

where the error $\delta_{o p}$ is the difference between the targeted output vector when compared with the neural network simulated vector for $k$ number of training samples. In the case when the MSE is less than the desired error, the neural network training is complete and the network is ready for prediction (KUMAR et al., 2014). A program supporting the generalized ANN GUI in MATLAB software has been developed. Thus, the validated network so developed can be used for reliable predictions using the test data set. Figure 1 shows the

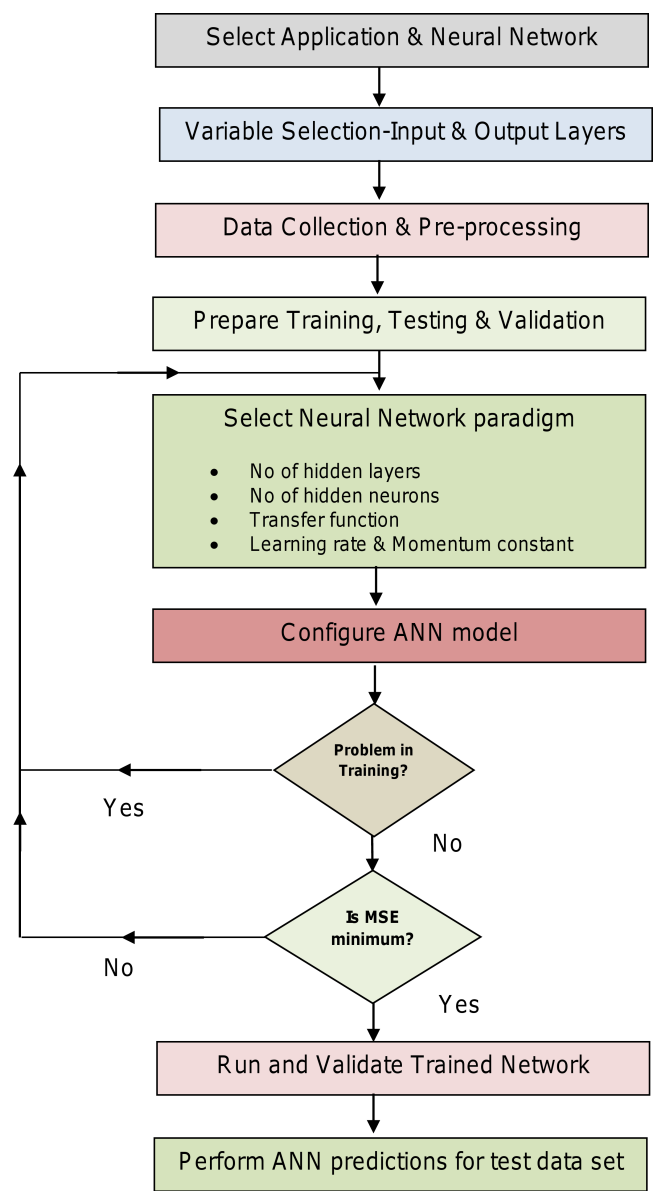

Fig. 1. Flow Chart of methodology for development of an ANN Model (GARG et al., 2015b). 
flow chart of methodology for development of an ANN Model (GARG et al., 2015b). The learning rate and momentum constant also play an important role in choosing an optimum model. The learning rate defines the size of the changes that are made to the weights and biases at each epoch. Generally, smaller value of learning rate increases the number of epochs and slows down the network convergence but produces better accuracy. Conversely, large value of learning rate leads the network to fast convergence but with less accuracy (Mustafa et al., 2015). The better and efficient convergence depends upon the choice of learning rate coefficient and momentum factor. The other way to improve the convergence with large learning rate is to add momentum factor to the previously changed weights as it smoothens the oscillatory behaviour of weights and leads to efficient rapid learning (Kumar et al., 2014). A high momentum factor can however cripple the network adaptability. Nevertheless, there is no theory that can be used to guide the selection of optimal ANN parameters. The trial-and-error methodology for specific problems is typically adopted by the most researchers which is the primary reason for inconsistencies in literature (ZHANG et al., 1998).

\section{Results and discussion}

Extensive simulations were performed to determine the best combination of parameters involving the network architecture and other parameters such as: learning rate, momentum constant, number of hidden neurons, learning algorithm and activation function. The network was trained with varying the neurons in a single hidden layer from 4 to 20 and each time the MSE and $R$ between the measured and predicted data were analyzed. The number of hidden neurons, number of hidden layers, learning rate, and momentum rate were sequentially optimized. Table 1 shows the network parameters used while training the network. An 13:14:1 architecture (13 neurons in input layer, 14 in hidden layer and 1 in output layer) provided the best prediction for the test data set. The optimal learning rate and momentum factor used in developing the ANN model were 0.6 and 0.1 respectively. Figures $2 \mathrm{a}$ and $2 \mathrm{~b}$ show the mean squared error and correlation coefficient of measured versus predicted data for different number of neurons a)

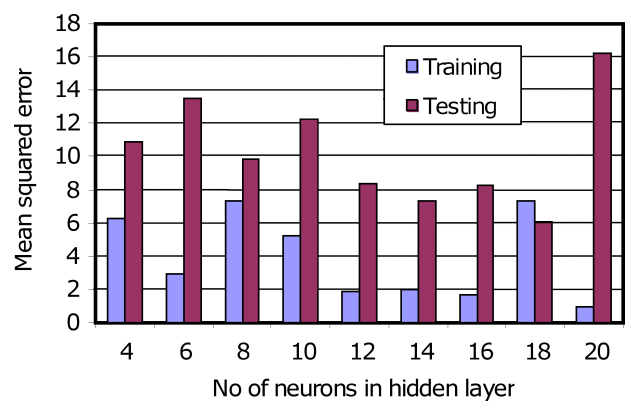

b)

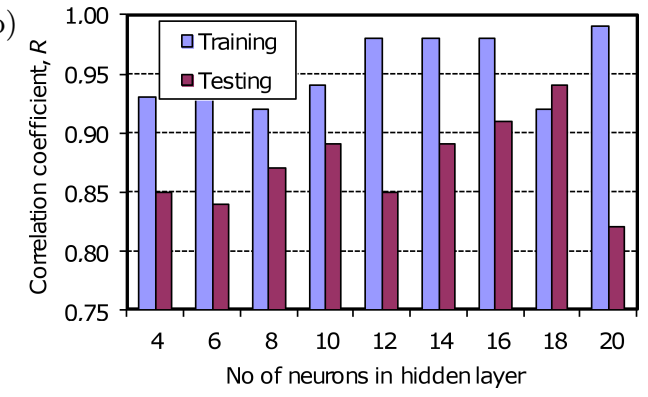

Fig. 2. Variation of Mean Squared Error (in point ${ }^{2}$ ) and correlation coefficient with number of neurons in a single hidden layer while training for development of an ANN model exclusively for STC predictions.

for the ANN model so developed for STC. It is evident that with 14 neurons in the hidden layer, both MSE and $R$ are optimized for testing and training data set. These investigations were repeated by training the network with changing the output parameters as $R_{w}$, while all other input parameters were kept the same. Training the network with varying number of neurons from 4 to 20 in a single hidden layer reveals that for 14 neurons, optimized performance is sought. Figures $3 \mathrm{a}$ and $3 \mathrm{~b}$ show the mean squared error and correlation coefficient of measured versus predicted data for different number of neurons for the ANN model so developed for $R_{w}$. Training network with 14 neurons in a single hidden layer shows that the MSE of $1.96 \mathrm{~dB}(\mathrm{~A})^{2}$ in training and $7.33 \mathrm{~dB}(\mathrm{~A})^{2}$ in testing STC, while a MSE of $1.88 \mathrm{~dB}(\mathrm{~A})^{2}$ in training and $6.62 \mathrm{~dB}(\mathrm{~A})^{2}$ in testing is observed for $R_{w}$. The correlation coefficient is observed to be 0.98 in training and 0.89 in testing for STC; while for $R_{w}$, the correlation coefficient is observed to be 0.98 in training and 0.92 in testing. Thus, the network architecture is finally chosen as 13:14:1 as shown in Fig. 4.

Table 1. Neural network paradigm used in training.

\begin{tabular}{|c|c|c|c|c|c|c|c|}
\hline $\begin{array}{c}\text { Sound insulation } \\
\text { parameter }\end{array}$ & $\begin{array}{c}\text { Structure } \\
\text { of ANN model }\end{array}$ & $\begin{array}{c}\text { Training } \\
\text { algorithm }\end{array}$ & $\begin{array}{c}\text { Activation } \\
\text { function }\end{array}$ & $\begin{array}{c}\text { MSE } \\
\text { (in } \mathrm{dB}(\mathrm{A})^{2} \text { for } R_{w} \\
\text { and points }\end{array}$ for STC) & \multicolumn{2}{|c|}{$\begin{array}{c}\text { Correlation coefficient } \\
R\end{array}$} \\
\hline & & & & Training & Testing & Training & Testing \\
\hline STC & $13: 14: 1$ & trainlm & logsig & 1.96 & 7.33 & 0.98 & 0.89 \\
\hline$R_{w}$ & $13: 14: 1$ & trainlm & logsig & 1.88 & 6.62 & 0.98 & 0.92 \\
\hline
\end{tabular}


a)

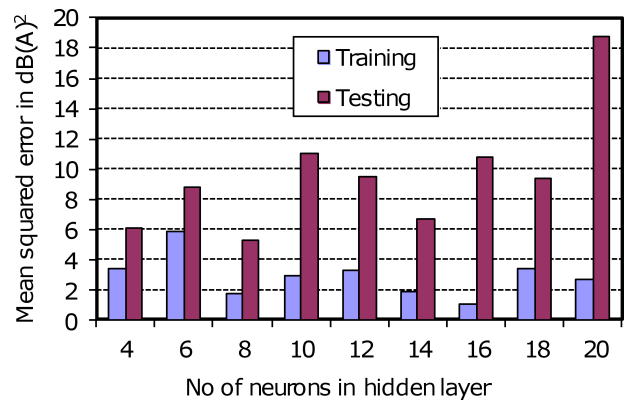

b)

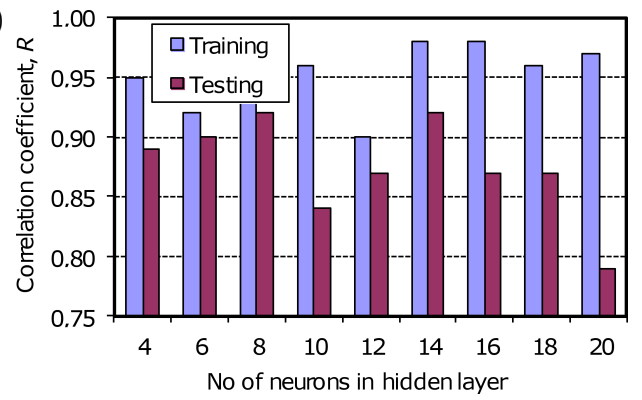

Fig. 3. Variation of Mean squared error (in $\left.\mathrm{dB}(\mathrm{A})^{2}\right)$ and Correlation coefficient with number of neurons in a single hidden layer while training for development of an ANN model exclusively for $R_{w}$ predictions.

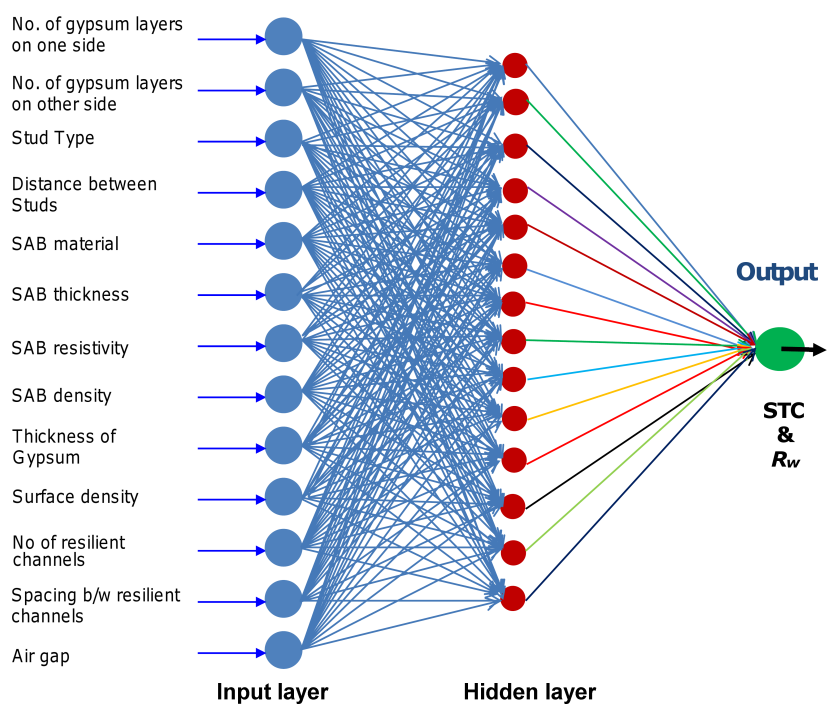

Fig. 4. Architecture of ANN model developed exclusively for $\mathrm{STC}$ and $R_{w}$.
Table 2 shows the error analysis of developed ANN models for STC and $R_{w}$. The Root Mean Squared Error (RMSE) observed in both cases is less than $2.0 \mathrm{~dB}(\mathrm{~A})$ and the coefficient of determination between the measured and predicted data is higher than 0.90 , which validates the suitability of the ANN model so developed. Thus, the results showed a good agreement with experimental data for both STC and $R_{w}$ of sandwich gypsum panels. The scatter plot of measured value of STC and $R_{w}$ in laboratory and the predicted value from the ANN model developed are shown in Figs. 5 and 6.

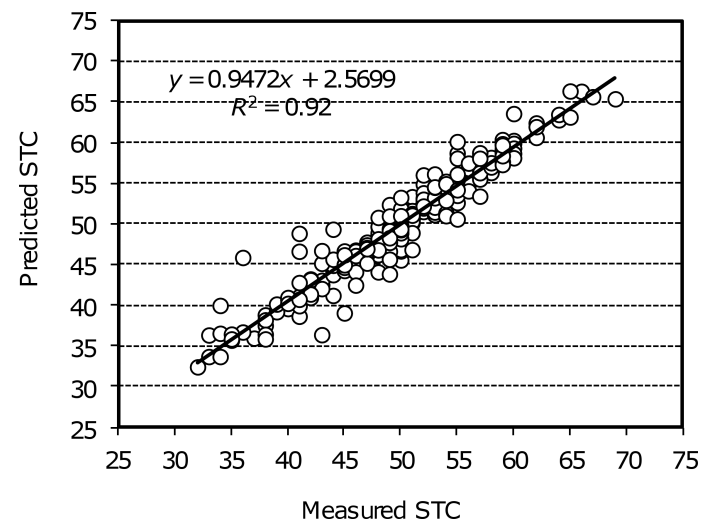

Fig. 5. Scatter plot of measured value in laboratory and predicted value of STC from the ANN model developed.

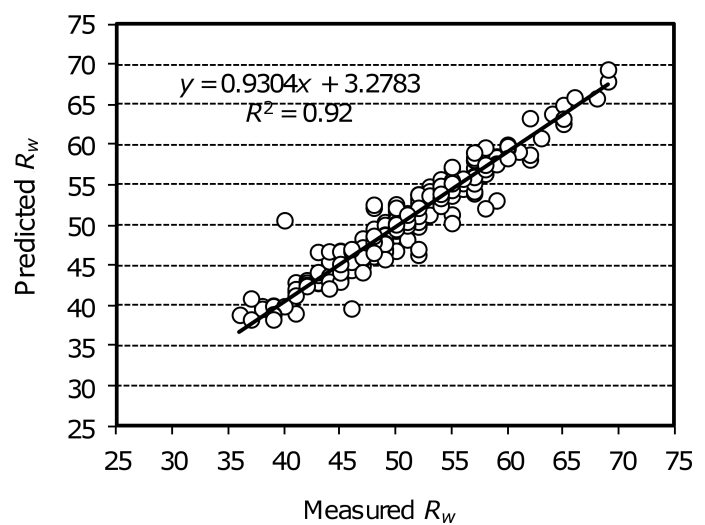

Fig. 6. Scatter plot of measured value of $R_{w}$ in laboratory and predicted value from the ANN model developed.

Table 2. Error analysis of the developed ANN model for sound reduction index and sound transmission class.

\begin{tabular}{|c|c|c|c|c|c|c|}
\hline $\begin{array}{c}\text { Sound } \\
\text { insulation } \\
\text { parameter }\end{array}$ & $\begin{array}{c}\text { Minimum } \\
\text { error } \\
\text { in } \mathrm{dB}(\mathrm{A}) \\
\text { for } R_{w} \\
\text { and points } \\
\text { for STC) }\end{array}$ & $\begin{array}{c}\text { Maximum } \\
\text { error } \\
\text { in } \mathrm{dB}(\mathrm{A}) \\
\text { for } R_{w} \\
\text { and points } \\
\text { for STC) }\end{array}$ & $\begin{array}{c}\text { Mean squared } \\
\text { error, MSE } \\
\text { (in dB(A) })^{2} \text { for } R_{w} \\
\text { and points } \\
\text { for STC) }\end{array}$ & $\begin{array}{c}\text { Root mean } \\
\text { squared } \\
\text { error, RMSE } \\
\text { (in dB(A) for } R_{w} \\
\text { and points } \\
\text { for STC) }\end{array}$ & $\begin{array}{c}\text { Mean absolute } \\
\text { percentage } \\
\text { error [\%] }\end{array}$ & $\begin{array}{c}\text { Coefficient } \\
\text { of determination } \\
R^{2}\end{array}$ \\
\hline STC & -7.0 & 10.0 & 3.4 & 1.9 & 0.1 & 0.3 \\
\hline$R_{w}$ & -6.0 & 11.0 & 2.8 & 1.7 & 0.3 & 0.92 \\
\hline
\end{tabular}


The ANN models developed are further validated with the results of paired $t$ test conducted (Table 3 ) for the predicted and measured single number ratings, STC and $R_{w}$. In this test, test statistic ( $t$-stat) is compared with $t$ critical and if $t$-stat value is within the $\pm t$ critical value for two-tailed test, it reveals that there is no significant difference between the two samples (accept null hypothesis). It is observed that for the ANN model, $t$-stat values are less than and far away from the critical values and are within the non-rejection region, which implies that predicted and measured data fits well (Montgomery, Runger, 2011; Pamanikabud, ViVITJINDA, 2002). Figures 7 and 8 show the frequency histogram indicating the frequency (in \%) of prediction error, i.e. difference between the measured and predicted STC and $R_{w}$ for 283 sandwich gypsum constructions. It is observed that for STC parameter, $88 \%$ observations show the prediction error of $\pm 2 \mathrm{~dB}$, while $94.7 \%$ observations show the prediction error of $\pm 3 \mathrm{~dB}$. $27.6 \%$ observations show no error between the measured and predicted STC value. Similarly for $R_{w}$ parameter, $90.8 \%$ observations show the prediction error of $\pm 2 \mathrm{~dB}$, while $98.2 \%$ observations show the prediction error of $\pm 3 \mathrm{~dB}$. $34.6 \%$ observations show no error between the measured and predicted $R_{w}$ value. Thus,

Table 3. Paired $t$-test for measured and predicted sound reduction index and sound transmission class.

\begin{tabular}{|l|c|c|}
\hline \multirow{2}{*}{ Statistical parameter } & Predicted values from ANN model \\
\cline { 2 - 3 } & STC & $R_{w}$ \\
\hline Mean absolute error & 0.10 & 0.21 \\
\hline Pearson correlation & 0.96 & 0.96 \\
\hline$d f$ & 282 & 282 \\
\hline$t$ Stat & 0.40 & 0.14 \\
\hline $\mathrm{P}(\mathrm{T}<=t)$ one-tail & 0.34 & 0.23 \\
\hline$t$ critical one-tail & 1.65 & 1.65 \\
\hline $\mathrm{P}(\mathrm{T}<=t)$ two-tail & 0.69 & 0.38 \\
\hline$t$ critical two-tail & 1.97 & 1.97 \\
\hline
\end{tabular}

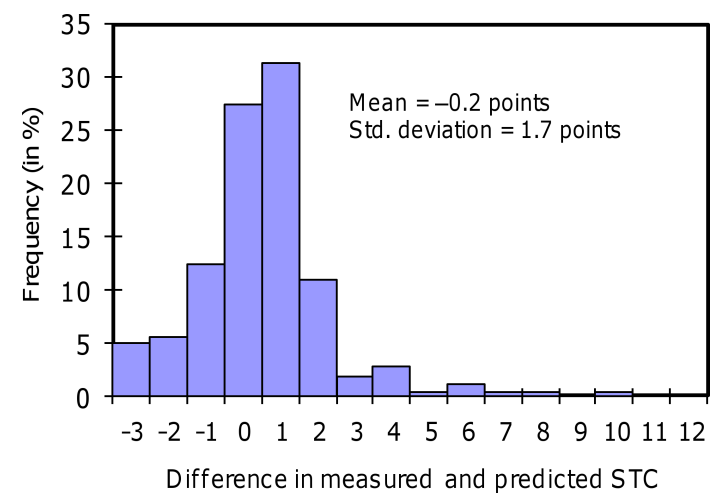

Fig. 7. Histogram showing the frequency (in \%) of prediction error, i.e. difference between the measured and predicted STC for 283 sandwich gypsum constructions.

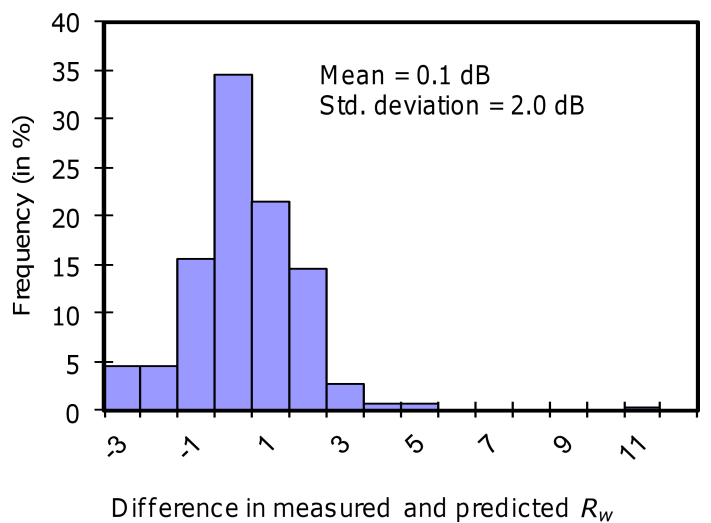

Fig. 8. Histogram showing the frequency (in \%) of prediction error, i.e. difference between the measured and predicted $R_{w}$ for 283 sandwich gypsum constructions.

it can be concluded that the developed ANN model shows a prediction error of $\pm 3 \mathrm{~dB}$ or points with a confidence level higher than $95 \%$. Also it is evident that the present ANN model shall be helpful for predictions of sound transmission loss properties of multilayered sandwich gypsum constructions with a reasonable accuracy without experimentation. Future efforts shall be focused on predicting the spectrum adaptation terms and single-number quantities proposed in the extended frequency range of $50 \mathrm{~Hz}$ to $5 \mathrm{kHz}$ using ANN modelling as described in the present work (SCHOLL et al., 2011; GARG et al., 2014b; GARG, MAJI, 2015a).

\section{Conclusions}

This paper aims to show an application of the Artificial Neural Networks technique in order to predict the acoustic performance of sandwich partition panels. The output of the developed ANN model is the STC and $R_{w}$ values of sandwich partition panels. The network was trained and tested on the basis of an experimental database consisting of 283 sandwich gypsum board panels tested at the Acoustics Laboratory, Institute for Research in Construction, National Research Council, Canada. The 13-14-1 neurons configuration was found to be optimal one. The validity of the model so developed is ascertained using statistical tests. The developed ANN model shows a prediction error of $\pm 3 \mathrm{~dB}$ or points with a confidence level higher than $95 \%$. The presented model can be thus applied to design and optimize acoustic performance of new products, by giving the appropriate values for input parameters of sandwich partition panels. The dynamic nature of ANN model thus offers an effective approach for predicting sound insulation properties of sandwich constructions. Undoubtedly, the inclusion of more experimental database of sandwich multi-layered constructions for training the network shall give a more comprehensive model at the price of feeding a more rigorous database. However, despite many advantages, 
there are some disadvantages too. Construction of an ANN model depends on the size of training data and network structure and sometimes it is like a black-box wherein one can't adjudge the weights and biases developed while training the network. However, in spite of these shortcomings, ANN can serve as vital substitute for analytical models for developing sandwich partition panels providing higher sound insulation, thus saving both money and time incurred on experimental testing in reverberation chambers.

\section{Acknowledgments}

Authors would specially acknowledge the NRC Canada reports of R.E. Halliwell (HALLIWELL et al., 1998; QUIRT et al., 1995) whose valuable data has been used for developing ANN model in this paper. Financial allocation by CSIR-National Physical Laboratory, India under the MIST project for the up-gradation of the Building Acoustics Measurement Facility is greatly acknowledged. The work was carried out under the Fast Track Translation (FTT) project of CSIR for the development of dry wall sandwich acoustical materials providing higher sound reduction index for noise abatement and control.

\section{References}

1. AcouSYS software (2017), CSTB France, http://www.cstb.fr/dae/en/nos-produits/logiciels/ acousys.html (accessed on 08.05.2017).

2. António J.M.P., Tadeu A., Godinho L. (2003), Analytical evaluation of the acoustic insulation provided by double infinite walls, Journal of Sound and Vibration, 263, 113-129.

3. ASTM E 90:1990, Standard Test Method for Laboratory Measurement of Airborne Sound Transmission Loss of Building Partitions and Elements, ASTM International, West Conshohocken.

4. ASTM-E413, Classification for Rating Sound Insulation, revised version in 2016, American Society for Testing and Materials, West Conshohocken.

5. BALlagh K.O. (2004), Accuracy of prediction methods for sound transmission loss, Proceedings of InterNoise 2004 Congress, Prague, Czech Republic (August 22-25, 2004), pp. 1--8.

6. Bradley J.S., Birta J.A. (2000), Laboratory measurements of the sound insulation of building facade elements, IRC Internal Report, IRC IR-818.

7. Bradley J.S., Birta J.A. (2001), On the sound insulation of wood stud exterior walls, Journal of Acoustical Society of America, 110, 3086-3096.

8. Bradley J.S., Gover B.N. (2011), Selecting walls for speech privacy, IRC report RR-314.

9. Buratti C., Barelli L., Moretti E. (2013), Wooden windows: Sound insulation evaluation by means of artificial neural networks, Applied Acoustics, 74, 740-745.

10. CAI M., Yin Y., XIE M. (2009), Prediction of hourly air pollutant concentrations near urban arterials using artificial neural network approach, Transportation Research Part D, 14, 32-41.

11. Craik R.J.M., Smith R.S. (2000), Sound transmission through double leaf lightweight partitions. Part I: airborne sound, Applied Acoustics, 61, 2, 223-245.

12. Crocker M., Price A.J. (1969), Sound transmission using statistical energy analysis, Journal of Sound and Vibration, 9, 3, 469-486.

13. Duch W., JANKowski N. (1999), Survey of neural network transfer functions, Neural Computing Surveys, 2, $163-212$.

14. Garg N., Kumar A., Maji S. (2013a), Parametric sensitivity analysis of factors affecting sound insulation of double glazing using Taguchi method, Applied Acoustics, 74, 1406-1413.

15. Garg N., Kumar A., Maji S. (2013b), Practical concerns associated with single number ratings in measuring sound transmission loss properties of partition panels, Archives of Acoustics, 38, 1, 115-124.

16. Garg N., Kumar A., Maji S. (2013c), Significance and implications of airborne sound insulation criteria in building elements for traffic noise abatement, Applied Acoustics, 74, 1429-1435.

17. Garg N., Kumar A., Maji S. (2014a), Parametric sensitivity analysis of factors affecting the sound insulation of multi-layered building elements, Archives of Acoustics, 39, 2, 165-176.

18. Garg N., Maji S. (2015a), On analyzing the correlations \& implications of single-number quantities for rating airborne sound insulation in frequency range $50 ; \mathrm{Hz}$ to $5 \mathrm{kHz}$, Journal of Building Acoustics, 22, 1 , 121-136.

19. Garg N., Mangal S.K., Saini P.K., Dhiman P., MAJI S. (2015b), Comparison of ANN and analytical models in traffic noise modeling and predictions, Journal of Acoustic Australia, 43, 179-189.

20. Garg N., Saxena T.K., Kumar A. (2014b), Uncertainty Evaluation and Implications of spectrum adaptation terms in determining the airborne sound insulation in building elements, Noise Control Engineering Journal, 39, 2, 165-176.

21. Garg N., Sharma M.K., Parmar K.S., Soni K., Singh R.K., Maji S. (2016), Comparison of ARIMA and ANN approach in time-series predictions of traffic noise, Noise Control Engineering Journal, 64, 4, 522531.

22. Ghaffari A., Abdollahi H., Khoshayand M.R., Bozchalooi I.S., Dadgar A., Rafiee-Tehrani M. (2006), Performance comparison of neural network training algorithms in modeling of bimodal drug delivery, International Journal of Pharmaceutics, 327, 126138. 
23. Givargis Sh., Karimi H. (2010), A basic neural traffic noise prediction model for Tehran's road, Journal of Environmental Management, 91, 2529-2534.

24. Guillen I., Uris A., Estella H., Llinares J., LlOPSIS A. (2008), On the sound insulation of masonry wall facades, Building and Environment, 43, 523-529.

25. Halliwell R.E., Nightingale T.R.T., WARNOCK A.C.C., BIRTA J.A. (1998), Gypsum board walls: Transmission loss data, National Research Council, Canada, Report No. IRC-IR-761.

26. Hush D.R., Horne B.G. (1993), Progress in supervised neural networks, IEEE Signal Processing Magazine, 10, 8-39.

27. Insul Software Manual (2017), http://www.insul.co.nz/download/Insulv6Manual.pdf (accessed on 08.03.2017).

28. ISO 140/III 1978 (E) (revised as ISO 10140-2:2010), Acoustics - Measurement of sound insulation in buildings and of building elements, Part 3: Laboratory measurements of airborne sound insulation of building elements.

29. Kumar P., Nigam S.P., Kumar N. (2014), Vehicular traffic noise modelling using artificial neural network approach, Transportation Research Part C, 40, 111122 .

30. KurRa S. (2012), Comparison of the models predicting sound insulation values of multilayered building elements, Applied Acoustics, 73, 575-589.

31. Kurra S., Arditi D. (2001), Determination of sound transmission loss of multilayered elements. Part 1: predicted and measured results, Acta Acustica, 87, 5, 582592.

32. LeCun Y.A., Bottou L., Orr G.B., Muller K.-R. (1998), Neural Networks: tricks of the trade, Lecture Notes in Computer Science, Springer, pp. 9-48.

33. Lin M., Tsai K., Su B. (2009), Estimating the sound absorption coefficients of perforated wooden panels by using artificial neural networks, Applied Acoustics, 70, 31-40.

34. Lyon R.H., DeJong R.G. (1995), Theory and application of statistical energy analysis, ButterworthHeinemann, 2nd ed.

35. MathWorks, Train and Apply Multilayer Neural Networks, http://in.mathworks.com/help/nnet/ug/trainand-apply-multilayer-neural-networks.html (accessed on 08.03.2017).

36. Montgomery D.C., Runger G.C. (2011), Applied Statistics and Probability for Engineers, 5th ed., Wiley, Ch. 10, pp. 351-394.

37. Mungiole M., Keith Wislon D. (2006), Prediction of outdoor sound transmission loss with an artificial neural network, Applied Acoustics, 67, 324-345.

38. Mustafa M.R., Rezaur I.R.B., Rahardjo H., IsA M.H., ARIF A. (2015), Artificial Neural Network Modeling for Spatial and Temporal Variations of Pore-Water Pressure Responses to Rainfall, Advances in Meteorology, Article ID 273730, 1-12. http://dx.doi.org/10.1155/2015/273730 (accessed on 08.03.2017).
39. Nannariello J., Fricke F.R. (1999), The prediction of reverberation time using neural network analysis, Applied Acoustics, 58, 305-325.

40. Nannariello J., Fricke F.R. (2001), A neural network analysis of effect of geometric variables on concert hall G values, Applied Acoustics, 62, 12, 1397-1410.

41. Nannariello J., Hodgon M., Fricke F.R. (2001), Neural network predictions of speech levels in university classrooms, Applied Acoustics, 62, 7, 749-767.

42. Nucara A., Pietrafesa M., Scaccianoce G., Staltari G. (2002), A comparison between analytical models and Artificial neural networks in the evaluation of traffic noise levels, Proceedings 17th International Congress on Acoustics, ICA Rome, pp. 208-209.

43. Pamanikabud P., Vivituinda P. (2002), Noise prediction for highways in Thailand, Transportation Res. Part D, 7, 441-449.

44. Park H.K., Bradley J.S. (2009), Evaluating standard airborne sound insulation measures in terms of annoyance, loudness and audibility ratings, Journal of Acoustical Society of America, 126, 1, 208-219.

45. Pellicier A., Trompette N. (2007), A review of analytical methods, based on the wave approach, to compute partitions transmission loss, Applied Acoustics, 68, 10, 1192-1212.

46. Quirt J.D., Warnock A.C.C., Birta J.A. (1995), Sound transmission through Gypsum board walls: Sound transmission results, IRC-IR-693, National Research Council, Canada.

47. Roozen N.B., Muellner H., Labelle L., Rychtáriková M., Glorieux C. (2015), Influence of panel fastening on acoustic performance of light-weight building elements: Study by sound transmission and laser scanning vibrometry, Journal of Sound and Vibration, 346, 100-116.

48. Scholl W., Lang J., Wittstock V. (2011), Rating of Sound Insulation at Present and in Future. The Revision of ISO 717, Acta Acustica united with Acustica, 97, 686-698.

49. Sharp B.H. (1978), Prediction methods for the sound transmission of building elements, Noise Control Engineering Journal, 11, 53-63.

50. Uris A., Llopis A., Llinares J. (1999), Effect of the rockwool bulk density on the airborne sound insulation of lightweight double walls Applied Acoustics, 58, 327331.

51. Wang T., Li S., Rajaram S., Nutt S.R. (2010), Predicting the sound transmission loss of sandwich panels by statistical energy analysis approach, ASME Journal of Vibration Acoustics, 132, 1, 011004-011004-7, doi:10.1115/1.4000459.

52. Wang T., Sokolinsky V.S., Rajaram S., Nutt S.R. (2005), Assessment of sandwich models for the prediction of sound transmission loss in unidirectional sandwich panels, Applied Acoustics, 66, 245-262.

53. WARNOCK A.C.C. (1985), Factors affecting sound transmission loss, Canadian Building Science Insight, Canadian Building Science Insight, CBD 239. 
54. WARNOCK A.C.C. (1990), Sound transmission loss measurement through $190 \mathrm{~mm}$ and $140 \mathrm{~mm}$ blocks with added dry wall and through cavity block walls, NRC Canada, Internal Report No. 586.

55. WARNOCK A.C.C. (1993), Sound transmission through slotted concrete blocks with attached gypsum board, National Research Council, Canada, Journal of the Acoustical Society of America, 94, 5, 2713-2720.

56. WARNOCK A.C.C. (1998), Controlling sound transmission through concrete block walls, Construction Technology Update No. 13, National Research Council of Canada.

57. WARNOCK A.C.C., QUIRT J.D. (1995), Sound transmission through gypsum board walls, Institute for Research in Construction, National Research Council of Canada, NRCC-38990, http://nparc.cisti-icist.nrccnrc.gc.ca/eng/view/accepted/?id=22916302-75be44e5-a7e9-b3b7ee485fe3 (accessed on 07.07.2017).

58. WARNOCK A.C.C., QUIRT J.D. (1997), Control of sound transmission through gypsum board walls, Construction Technology Updated No. 1, Institute for Research in Construction, National Research Council of Canada. http://www.nrc-cnrc.gc.ca/ctusc/files/doc/ctu-sc/ctu-n1_eng.pdf (accessed on 08.03.2017).

59. Zhang G., Patuwo B.E., Hu M.Y. (1998), Forecasting with artificial neural networks: The state of art, International Journal of Forecasting, 14, 35-62.

60. Zhou J., Bhaskar A., Zhang X. (2013), Optimization for sound transmission through a double-wall panel, Applied Acoustics, 74, 12, 1422-1428. 